\title{
PENGARUH KARAKTERISTIK INDIVIDU DAN KARAKTERISTIK PEKERJAAN TERHADAP KINERJA KARYAWAN PADA KOPERASI SIMPAN PINJAM “ABDI KARYA SEJAHTERA" KENDARI
}

\author{
Wa Ode Hardiyanty Lenna ${ }^{1}$, Ansir $^{2}$, dan Riski Amalia Madi ${ }^{2}$ \\ 1. Mahasiswi Jurusan Manajemen FEB UHO \\ 2. Staf Pengajar Jurusan Manajemen FEB UHO \\ Email: dianlfzahron@gmail.com
}

\begin{abstract}
ABSTRAK
Penelitian ini bertujuan untuk menjelaskan dan menguji secara empiris pengaruh karakteristik individu dan karakteristik pekerjaan terhadap kinerja karyawan pada koperasi simpan pinjam "Abdi karya Sejahtera" Kendari. Teknik Pengambilan sampel yang digunakan adalah sensus, yaitu teknik penentuan responden dengan mengambil semua jumlah populasi dalam penelitian. sampel dalam penelitian ini adalah 32 responden. Metode analisis data yang digunakan adalah deskriptif kuantitatif. Alat analisis yang digunakan adalah regresi linear berganda. Dengan menggunakan SPSS 24.

Hasil penelitian ini menyatakan bahwa: secara simultan variabel karakteristik individu dan karakteristik pekerjaan berpengaruh signifikan terhadap kinerja karyawan pada Koperasi Simpan Pinjam "Abdi Karya Sejahtera" Kendari. Karakteristik individu berpengaruh signifikan terhadap kinerja karyawan pada Koperasi Simpan Pinjam "Abdi Karya Sejahtera” Kendari. Karakteristik pekerjaan berpengaruh signifikan terhadap kinerja karyawan pada Koperasi Simpan Pinjam "Abdi Karya Sejahtera" Kendari.
\end{abstract}

Kata kunci: Karakteristik individu, Karakteristik pekerjaan, Kinerja

\begin{abstract}
This study aims to explain and test empirically the influence of individual characteristics and job characteristics on employee performance in the cooperative savings and loan "Abdi Karya Sejahtera" Kendari. The sampling technique used census, which is technique to determine the respondents of total population in the study. The sample in this study were 32 respondents. Data anaslysis method used quantitative descriptive analysis. The analysis used tool multiple linear regression. With use SPSS 24.

Result research stated that on simultaneously variable of individual characteristics and job characteristics have an effect on signifikan to employee performance in the cooperative savings and loan "Abdi Karya Sejahtera" Kendari. Individual characteristics have a significant effect on the performance of employees in the cooperative savings and loan "Abdi Karya Sejahtera" Kendari. Job characteristics have a significant effect on the performance of employees in the cooperative savings and loan "Abdi Karya Sejahtera" kendari.
\end{abstract}

Keywords: Individual characteristics, Job characteristics, Performance 


\section{PENDAHULUAN}

Pada era globalisasi ini, sejalan dengan perkembangan ilmu pengetahuan dan teknologi suatu perusahaan tidak dapat lagi menghindari persaingan dengan perusahaan lain. Suatu perusahaan yang ingin berkembang harus mampu memanfaatkan sumberdaya yang telah ada secara optimal. Kondisi tersebut menuntut suatu organisasi atau perusahaan untuk senantiasa melakukan berbagai inovasi guna mengantisipasi adanya persaingan yang semakin ketat.

Untuk mendorong berkembangnya suatu perusahaan atau organisasi dan meningkatkan kualitas perusahaan atau organisasi, maka harus ada pengelolaan sumber daya manusia / karyawan yang baik. Tanpa adanya peran sumber daya manusia, organisasi tidak akan dapat melaksanakan kegiatan untuk pencapaian tujuan dari organisasi itu. Tentunya tujuan organisasi akan mudah tercapai apabila didorong dengan peningkatan potensi sumber daya manusia. Peningkatan tersebut dipengaruhi oleh beberapa faktor yang salah satunya karakteristik individu (Rendi dkk., 2014).

Menurut Robins (2003) karateristik individu merupakan perbedaan dari masing-masing karyawan sehingga mempengaruhi dalam perilaku kerja. Karakteristik individu yang berbeda-beda merupakan latar belakang yang dibawa individu dalam melakukan pekerjaanya sehingga tingkat kinerjanyapun berbeda-beda.

Selain karateristik individu ada yang mempengaruhi terhadap kinerja karyawan dalam suatu badan atau organisasi yaitu karakteristik pekerjaaan (Hadrane, 2017). Karakteristik pekerjaan yang berbeda memerlukan persyaratan kecakapan, identitas tugas, signifikansi tugas serta derajat otonomi yang berbeda pula (Stoner, 2006: 423). Kinerja merupakan hasil kerja yang dapat dicapai seseorang atau sekelompok orang dalam suatu organisasi dalam rangka mencapai tujuan organisasi dalam periode waktu tertentu (Tika, 2006: 121).

Koperasi Simpan Pinjam adalah merupakan lembaga keuangan bukan bank. Koperasi ini adalah koperasi yang bergerak di bidang simpanan dan pinjaman. Koperasi sejenis ini didirikan dengan mudah dan bunga ringan. Menurut Widiyanti dan Sunindhia (2008), Koperasi simpan pinjam memiliki tujuan untuk anggotanya hidup berhemat dan juga menambah pengetahuan anggotanya terhadap koperasian.

Koperasi Simpan Pinjam "Abdi Karya Sejahtera" Kendari merupakan Koperasi simpan pinjam yang berkembang pesat di Sulawesi Tenggara. Hal ini terbukti dengan mempunyai beberapa anak cabang yang dimiliki. Berdasarkan data pra penelitian diperoleh informasi bahwa adanya karyawan Koperasi Simpan Pinjam "Abdi Karya Sejahtera" Kendari kinerja yang dihasilkan kurang optimal seperti yang diinginkan. Misalnya, masih ada karyawan yang pekerjaan yang seharusnya selesai dalam waktu yang cepat akan tetapi pekerjaan tersebut tidak dapat terselesaikan. Hal ini akan membuat hasil kinerja karyawan akan mengalami penurunan. Fenomena ini tentunya merupakan salah satu dari sekian banyak fenomena yang terjadi yang ada kaitanya dengan masalah kinerja karyawan.

Berdasarkan fenomena diatas maka saya tertarik untuk melakukan penelitian dengan judul "Pengaruh karakteristik individu dan karakteristik pekerjaan terhadap kinerja karyawan pada Koperasi Simpan Pinjam " Abdi Karya Sejahtera" Kendari ".

\section{METODE PENELITIAN}

\section{Lokasi Penelitian}

Lokasi penelitian ini adalah Koperasi Simpan Pinjam "Abdi Karya Sejahtera" Kendari, yang terletak di Jalan Manggis No. 10.

\section{Populasi dan Sampel Penelitian}

Populasi penelitian ini adalah seluruh karyawan Koperasi Simpan Pinjam "Abdi Karya Sejahtera" Kendari sebanyak 32 orang. Jumlah populasi dalam penelitian ini, sekaligus sebagai sampel dalam penelitian ini dengan menggunakan teknik sensus.

\section{Jenis dan Sumber Data}

Jenis data yang digunakan adalah data kualitatif yaitu data yang berupa penjelasan deskriptif seperti literatur-literatur serta teori-teori yang berkaitan dengan penelitian penulis, dan data kuantitatif yaitu data yang berbentuk angka-angka. Dalam hal ini berupa data laporan jumlah karyawan serta data 
kuantitatif lainya yang berhubungan dengan penelitian ini. Sedangkan sumber data dalam penelitian ini yaitu sumber data primer dan data sekunder.

\section{Metode Pengumpulan Data dan Analisis Data}

Metode pengumpulan data yang digunakan dalam penelitian ini yaitu melalui wawancara kuesioner dan interview. Skala pengukuran yang digunakan yaitu skala likert untuk mengukur sikap, pendapat, dan presepsi terhadap suatu objek.

Teknik yang digunakan adalah teknik analisis statistik deskriptif dan statistik inferensial. Analisis statistik deskriptif ditujukan untuk memperoleh gambaran tentang kondisi Kantor Koperasi Simpan Pinjam "Abdi Karya Sejahtera" Kendari untuk mengindentifikasi karakteristik masing-masing variabel dalam bentuk frekuensi dan persentase.
Sedangkan analisis statistik dengan menggunakan statistik inferensial adalah menggunakan analisis regresi linear berganda, dimana dalam penelitian ini digunakan untuk mengetahui pengaruh variabel karakteristik individu, karakteristik pekerjaan terhadap variabel kinerja karyawan pada Koperasi Simpan Pinjam "Abdi Karya Sejahtera" Kendari.

\section{HASIL DAN PEMBAHASAN}

\section{Deskripsi Variabel Karakteristik Individu}

Pengukuran variabel karakteristik individu dengan empat (4) item indikator pernyataan. Rekapitulasi distribusi jawaban responden atas variabel karakteristik individu akan dijelaskan sebagai berikut pada Tabel 1:

Tabel 1. Rekapitulasi Jawaban Atas Variabel Karakteristik Individu $\left(\mathrm{X}_{1}\right)$

\begin{tabular}{|c|c|c|c|c|c|c|c|c|c|c|c|c|c|c|}
\hline \multirow{3}{*}{ Indikator } & \multirow{3}{*}{ item } & \multicolumn{13}{|c|}{ Jawaban Responden } \\
\hline & & \multicolumn{2}{|c|}{ SS } & \multicolumn{2}{|c|}{$\mathbf{S}$} & \multicolumn{2}{|c|}{$\mathbf{N}$} & \multicolumn{2}{|c|}{ TS } & \multicolumn{2}{|c|}{ STS } & \multicolumn{2}{|c|}{ Jumlah } & \multirow{2}{*}{$\begin{array}{c}\text { Rata- } \\
\text { rata }\end{array}$} \\
\hline & & f & $\%$ & $\mathbf{f}$ & $\%$ & $\mathbf{f}$ & $\%$ & $\mathbf{F}$ & $\%$ & $\mathbf{F}$ & $\%$ & SS/S/N/TS & $\%$ & \\
\hline \multirow{9}{*}{ Kemampuan } & $\mathrm{X} 1.1$ & 9 & 28.1 & 18 & 56.3 & 4 & 12.5 & 1 & 3.1 & 0 & 0.0 & \multirow{9}{*}{288} & \multirow{9}{*}{824.6} & 4.09 \\
\hline & $\mathrm{X} 1.2$ & 23 & 71.9 & 8 & 25.0 & 1 & 3.1 & 0 & 0.0 & 0 & 0.0 & & & 4.69 \\
\hline & $\mathrm{X} 1.3$ & 14 & 43.8 & 15 & 46.9 & 3 & 9.4 & 0 & 0.0 & 0 & 0.0 & & & 4.34 \\
\hline & $\mathrm{X} 1.4$ & 22 & 68.8 & 9 & 28.1 & 1 & 3.1 & 0 & 0.0 & 0 & 0.0 & & & 4.66 \\
\hline & $\mathrm{X} 1.5$ & 17 & 53.1 & 14 & 43.8 & 1 & 3.1 & 0 & 0.0 & 0 & 0.0 & & & 4.50 \\
\hline & X1.6 & 8 & 25.0 & 18 & 56.3 & 5 & 15.6 & 1 & 3.1 & 0 & 0.0 & & & 4.03 \\
\hline & $\mathrm{X} 1.7$ & 16 & 50.0 & 13 & 40.6 & 3 & 9.4 & 0 & 0.0 & 0 & 0.0 & & & 4.41 \\
\hline & $\mathrm{X} 1.8$ & 21 & 65.5 & 10 & 31.3 & 1 & 3.1 & 0 & 0.0 & 0 & 0.0 & & & 4.63 \\
\hline & X1.9 & 14 & 43.8 & 17 & 53.1 & 1 & 3.1 & 0 & 0.0 & 0 & 0.0 & & & 4.41 \\
\hline \multicolumn{12}{|c|}{ Rata-rata indikator } & & & 4.42 \\
\hline \multirow{3}{*}{ Nilai } & $\mathrm{X} 110$ & 12 & 37.5 & 17 & 53.1 & 3 & 9.4 & 0 & 0.0 & 0 & 0.0 & \multirow{3}{*}{94} & \multirow{3}{*}{206.2} & 4.28 \\
\hline & $\mathrm{X} 1.11$ & 13 & 40.6 & 19 & 59.4 & 0 & 0.0 & 0 & 0.0 & 0 & 0.0 & & & 4.41 \\
\hline & $\mathrm{X} 1.12$ & 12 & 37.5 & 13 & 40.6 & 5 & 15.6 & 0 & 0.0 & 0 & 0.0 & & & 4.09 \\
\hline \multicolumn{12}{|c|}{ Rata-rata indikator } & & & 4.26 \\
\hline \multirow{3}{*}{ Sikap } & $\mathrm{X} 1.13$ & 14 & 43.8 & 18 & 56.3 & 1 & 3.1 & 0 & 0.0 & 0 & 0.0 & \multirow{3}{*}{97} & \multirow{3}{*}{301.3} & 4.34 \\
\hline & $\mathrm{X} 1.14$ & 14 & 43.8 & 17 & 53.1 & 1 & 3.1 & 0 & 0.0 & 0 & 0.0 & & & 4.41 \\
\hline & $\mathrm{X} 1.15$ & 18 & 56.3 & 13 & 40.6 & 1 & 3.1 & 0 & 0.0 & 0 & 0.0 & & & 4.53 \\
\hline \multicolumn{12}{|c|}{ Rata-rata indikator } & \multirow{4}{*}{96} & & 4.43 \\
\hline \multirow{3}{*}{ Minat } & $\mathrm{X} 1.16$ & 13 & 40.6 & 18 & 56.3 & 1 & 3.1 & 0 & 0.0 & 0 & 0.0 & & \multirow{3}{*}{300,0} & 4.38 \\
\hline & $\mathrm{X} 1.17$ & 14 & 43.8 & 13 & 40.6 & 5 & 15.6 & 0 & 0.0 & 0 & 0.0 & & & 4.28 \\
\hline & $\mathrm{X} 1.18$ & 17 & 53.1 & 10 & 31.3 & 4 & 12.5 & 1 & 3.1 & 0 & 0.0 & & & 4.34 \\
\hline \multicolumn{12}{|c|}{ Rata-rata indikator } & & & 4.33 \\
\hline \multicolumn{12}{|c|}{ Rata-rata variabel } & 144 & 408 & 4.38 \\
\hline
\end{tabular}

Sumber: Data primer (diolah, 2018) 
Berdasarkan hasil analisis deskriptif, variabel karakteristik individu $\left(\mathrm{X}_{1}\right)$, mempunyai rata-rata skor jawaban responden 4,43 atau berada pada kategori sangat baik. Hal ini menunjukan bahwa karakteristik individu pada karyawan Koperasi Simpan Pinjam "Abdi Karya Sejahtera" Kendari yang dinilai berdasarkan persepsi responden atas kemampuan yang terdiri dari ( kemampuan teknis, kemampuan sosial, kemampuan konseptual), nilai, sikap, minat dan dari 4 item indikator tersebut masing-masing terdiri dari 3 item pernyataan. Dari 18 item pernyataan yang ada, menunjukan bahwa terdapat 2 jawaban responden yang menjawab angka 2 (tidak setuju).

Namun, secara umum responden menunjukan bahwa rata-rata semua item pada variabel karakteristik individu itu berada pada daerah positif yang berarti bahwa karakteristik individu pada karyawan Koperasi Simpan Pinjam "Abdi Karya Sejahtera" Kendari telah dapat mempengaruhi peningkatan kinerja karyawan dalam menunjang pencapaian tujuan organisasi

\section{Deskripsi Variabel Karakteristik Pekerjaan}

Pengukuran variabel karakteristik pekerjaan dengan lima (5) item indikator pernyataan. Rekapitulasi distribusi jawaban responden atas variabel karakteristik pekerjaan pada Tabel 2.

Tabel 2. Rekapitulasi Jawaban Atas Variabel Karakteristik Pekerjaan $\left(\mathbf{X}_{2}\right)$

\begin{tabular}{|c|c|c|c|c|c|c|c|c|c|c|c|c|c|c|}
\hline \multirow{3}{*}{ Indikator } & \multirow{3}{*}{ item } & \multicolumn{13}{|c|}{ Jawaban Responden } \\
\hline & & \multicolumn{2}{|c|}{ SS } & \multicolumn{2}{|c|}{$\mathrm{S}$} & \multicolumn{2}{|r|}{$\mathrm{N}$} & \multicolumn{2}{|c|}{ TS } & \multicolumn{2}{|c|}{ STS } & \multicolumn{2}{|c|}{ Jumlah } & \multirow{2}{*}{$\begin{array}{l}\text { Rata- } \\
\text { rata }\end{array}$} \\
\hline & & $\mathrm{F}$ & $\%$ & $\mathrm{f}$ & $\%$ & $\mathrm{f}$ & $\%$ & $\mathrm{~F}$ & $\%$ & $\mathrm{~F}$ & $\%$ & SS/S/N/TS & $\%$ & \\
\hline \multirow{4}{*}{$\begin{array}{l}\text { Keanekaragaman } \\
\text { Keterampilan }\end{array}$} & $\mathrm{X} 2.1$ & 14 & 43,8 & 17 & 53,1 & 1 & 3.1 & 0 & 0.0 & 0 & 0.0 & \multirow{3}{*}{93} & \multirow{3}{*}{290.8} & 4.41 \\
\hline & $\mathrm{X} 2.2$ & 10 & 31,3 & 15 & 46,9 & 4 & 12.5 & 3 & 9.4 & 0 & $0 . ` 0$ & & & 4.00 \\
\hline & $\mathrm{X} 2.3$ & 14 & 43,8 & 15 & 46,9 & 3 & 9.4 & 0 & 0.0 & 0 & 0.0 & & & 4.34 \\
\hline & \multicolumn{11}{|c|}{ Rata-rata indikator } & & & 4.25 \\
\hline \multirow{4}{*}{$\begin{array}{l}\text { Identitas } \\
\text { Tugas }\end{array}$} & $\mathrm{X} 2.4$ & 16 & 50.0 & 13 & 40.6 & 3 & 9.4 & 0 & 0.0 & 0 & 0.0 & \multirow{3}{*}{93} & \multirow{3}{*}{291.2} & 4.41 \\
\hline & $\mathrm{X} 2.5$ & 11 & 34.4 & 16 & 50.5 & 5 & 15.6 & 0 & 0.0 & 0 & 0.0 & & & 4.19 \\
\hline & $\mathrm{X} 2.6$ & 14 & 43.8 & 6 & 18.8 & 9 & 28.1 & 3 & 9.4 & 0 & 0.0 & & & 3.97 \\
\hline & \multicolumn{11}{|c|}{ Rata-rata indikator } & & & 4.19 \\
\hline \multirow{4}{*}{$\begin{array}{c}\text { Signifikansi } \\
\text { Tugas }\end{array}$} & $\mathrm{X} 2.7$ & 15 & 46.9 & 14 & 43.8 & 3 & 9.4 & 0 & 0.0 & 0 & 0.0 & \multirow{3}{*}{88} & \multirow{3}{*}{275.1} & 4.38 \\
\hline & $\mathrm{X} 2.8$ & 12 & 37.5 & 10 & 31.3 & 5 & 15.6 & 5 & 15.6 & 0 & 0.0 & & & 3.91 \\
\hline & $\mathrm{X} 2.9$ & 11 & 34.3 & 12 & 37.5 & 6 & 18.8 & 3 & 9.4 & 0 & 0.0 & & & 3.97 \\
\hline & \multicolumn{10}{|c|}{ Rata-rata indikator } & & & & 4.09 \\
\hline \multirow{4}{*}{ Otonomi } & $\mathrm{X} 210$ & 5 & 15.6 & 17 & 53.1 & 6 & 18.8 & 4 & 12.5 & 0 & 0.0 & \multirow{3}{*}{86} & \multirow{3}{*}{268.8} & 3.72 \\
\hline & $\mathrm{X} 2.11$ & 7 & 21.9 & 15 & 46.9 & 5 & 15.6 & 5 & 15.6 & 0 & 0.0 & & & 3.75 \\
\hline & $\mathrm{X} 2.12$ & 13 & 40.6 & 15 & 46.9 & 3 & 9.4 & 1 & 3.1 & 0 & 0.0 & & & 4.25 \\
\hline & \multicolumn{11}{|c|}{ Rata-rata indikator } & & & 3.91 \\
\hline \multirow{5}{*}{ Umpan Balik } & $\mathrm{X} 2.13$ & 7 & 21.9 & 19 & 59.4 & 4 & 12.5 & 2 & 6.3 & 0 & 0.0 & \multirow{3}{*}{90} & \multirow{3}{*}{93.8} & 3.97 \\
\hline & $\mathrm{X} 2.14$ & 3 & 9.4 & 18 & 56.3 & 7 & 21.9 & 4 & 12.5 & 0 & 0.0 & & & 3.63 \\
\hline & $\mathrm{X} 2.15$ & 9 & 28.1 & 20 & 62.5 & 3 & 94 & 0 & 0.0 & 0 & 0.0 & & & 4.19 \\
\hline & \multicolumn{11}{|c|}{ Rata-rata indikator } & & & 3.93 \\
\hline & & & & & ata-ra & 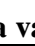 & riabel & & & & & 90,0 & 243.9 & 4.07 \\
\hline
\end{tabular}

Sumber : Data primer (diolah, 2018) 
Berdasarkan hasil analisis deskriptif , variabel karakteristik pekerjaan $\left(\mathrm{X}_{2}\right)$ mempunyai rata-rata skor jawaban responden sebesar 4,07 atau berada pada kategori baik. Hal ini menunjukan bahwa karakteristik pekerjaan yang dimiliki karyawan selama bekerja pada Koperasi Simpan Pinjam "Abdi Karya Sejahtera" Kendari terhadap keanekaragaman keterampilan, identitas tugas, signifikansi tugas, otonomi dan umpan balik dan dari 5 item indikator tersebut masing-masing terdiri dari 3 item pernyataan. Ada sebagian kecil responden menjawab netral.

Namun, secara umum responden menunjukan bahwa semua item pada variabel itu berada pada daerah yang positif yang berarti bahwa karakteristik pekerjaan yang dimiliki oleh karyawan Koperasi Simpan Pinjam "Abdi Karya Sejahtera" Kendari telah dapat mempengaruhi peningkatan kinerja dalam menunjang organisasi.

\section{Kinerja Karyawan (Y)}

Pengukuran variabel kinerja karyawan dengan tiga (3) item indikator pernyataan. Rekapitulasi distribusi jawaban responden atas variabel karakteristik pekerjaan akan dijelaskan pada Tabel 3.

Tabel 3. Rekapitulasi Jawaban Atas variabel Kinerja Karyawan (Y)

\begin{tabular}{|c|c|c|c|c|c|c|c|c|c|c|c|c|c|}
\hline \multirow{3}{*}{ item } & \multicolumn{13}{|c|}{ Jawaban Responden } \\
\hline & \multicolumn{2}{|c|}{ SS } & \multicolumn{2}{|r|}{$S$} & \multicolumn{2}{|c|}{$\mathrm{N}$} & \multicolumn{2}{|c|}{ TS } & \multicolumn{2}{|c|}{ STS } & \multicolumn{2}{|c|}{ Jumlah } & \multirow{2}{*}{$\begin{array}{l}\text { Rata- } \\
\text { rata }\end{array}$} \\
\hline & $\mathrm{f}$ & $\%$ & $\mathrm{f}$ & $\%$ & $\mathrm{f}$ & $\%$ & $\mathrm{~F}$ & $\%$ & $\mathrm{~F}$ & $\%$ & $\mathrm{SS} / \mathrm{S} / \mathrm{N} / \mathrm{TS}$ & $\%$ & \\
\hline Y1.1 & 20 & 62.5 & 10 & 31.3 & 1 & 3.1 & 1 & 3.1 & 0 & 0.0 & \multirow{3}{*}{81} & \multirow{3}{*}{300.3} & 4.53 \\
\hline $\mathrm{Y} 1.2$ & 10 & 31.3 & 19 & 59.4 & 3 & 9.4 & 0 & 0.0 & 0 & 0.0 & & & 4.22 \\
\hline Y1.3 & 14 & 43.8 & 13 & 40.6 & 5 & 15.8 & 0 & 0.0 & 0 & 0.0 & & & 4.28 \\
\hline \multicolumn{11}{|c|}{ Rata-rata indikator } & & & 4.34 \\
\hline Y1.4 & 15 & 46.9 & 16 & 50.0 & 1 & 3.1 & 0 & 0.0 & 0 & 0.0 & \multirow{2}{*}{64} & \multirow{2}{*}{190.6} & 4.44 \\
\hline Y1.5 & 21 & 65.6 & 9 & 28.1 & 2 & 6.3 & 0 & 0.0 & 0 & 0.0 & & & 4.59 \\
\hline \multicolumn{11}{|c|}{ Rata-rata indikator } & \multirow{3}{*}{64} & & 4.44 \\
\hline Y1.6 & 13 & 40.6 & 16 & 50.0 & 3 & 9.4 & 0 & 0.0 & 0 & 0.0 & & \multirow{2}{*}{200.1} & 4.31 \\
\hline Y1.7 & 20 & 62.5 & 10 & 31.3 & 2 & 6.3 & 0 & 0.0 & 0 & 0.0 & & & 4.56 \\
\hline \multicolumn{11}{|c|}{ Rata-rata indikator } & & & 4.56 \\
\hline \multicolumn{11}{|c|}{ Rata-rata variabel } & 69,6 & 230.3 & 4.42 \\
\hline
\end{tabular}

Sumber : Data primer (diolah, 2018)

Berdasarkan hasil analisis deskriptif, variabel kinerja karyawan (Y) mempunyai rata-rata skor jawaban 4.42 atau berada pada kategori sangat baik. Hal ini menunjukan bahwa dari 7 item pernyataan yang ada menunjukan bahwa terdapat jawaban responden yang menjawab 1 orang atau tidak setuju. Namun, jika diperhatikan rata-rata semua item pada variabel kinerja karyawan ini mempunyai rata-rata item berada pada daerah positif yang berarti bahwa kinerja baik telah ditunjukkan karyawan Koperasi Simpan Pinjam "Abdi Karya Sejahtera" Kendari dalam menunjang pencapaian tujuan perusahaan. Artinya, bahwa karyawan Koperasi Simpan Pinjam "Abdi Karya Sejahtera" Kendari dapat melaksanakan tugas dengan baik, jika dilihat dari segi kualitas, kuantitas dan ketepatan waktu.

\section{Hasil Pengujian Model Regresi}

Untuk membuktikan hipotesis penelitian yang diajukan dalam penelitian ini, digunakan metode regresi linear berganda dengan hasil analisis pada Tabel 4:

Berdasarkan hasil-hasil perhitungan menggunakan program SPSS 24,0 yang disajikan pada tabel 4.12 tersebut maka dapat dikemukakan penjelasan sebagi berikut : 
Tabel 4 Hasil Analisis Regresi Berganda

\begin{tabular}{|l|c|c|c|}
\hline \multicolumn{1}{|c|}{ Variabel } & $\begin{array}{c}\text { Koifisien } \\
\text { regresi }\end{array}$ & $\begin{array}{c}\mathbf{t} \\
\text { Hitung }\end{array}$ & $\begin{array}{c}\text { t } \\
\text { Signifikan }\end{array}$ \\
\hline Karakteristik Individu & 0,456 & 2,968 & 0,006 \\
\hline Karakteristik Pekerjaan & 0,355 & 2,311 & 0,028 \\
\hline Nilai Konstan $=0,264$ nilai signifikan 0,000 & & $\mathrm{~N}=32$ \\
$\mathrm{R} \quad=0,711$ & & $\alpha=0,05$ \\
R Square $=0,505$ & & \\
F Hitung $=14,795$ & & \\
F Signifikan $=0,000$ & & \\
Standar error $=0,338$ & & \\
\hline
\end{tabular}

Sumber: Hasil Analisis Statistik (SPSS)

1. Nilai R (angka koefisien korelasi) sebesar 0,711 menunjukan bahwa keeratan hubungan langsung antara karakteristik individu dan karakteristik pekerjaan terhadap kinerja karyawan adalah sebesar $71,1 \%$.

2. Nilai $\mathrm{R}^{2}$ ( $\mathrm{R}_{\text {square}}$ sebesar 0,505 menunjukan bahwa besarnya pengaruh langsung variabel karakteristik individu dan karakteristik pekerjaan terhadap variabel kinerja karyawan adalah sebesar 50,5\%. Hal ini menunjukan bahwa 50,5\% kinerja karyawan dapat dijelaskan oleh variabel karakteristik individu dan karakteristik pekerjaan terhadap kinerja karyawan. Sedangkan sisanya 49,5\% dipengaruhi oleh variabel lain yang tidak dimasuk`an dalam model penelitian ini.

Dengan demikian maka model regresi yang menyatakan pengaruh karakteristik individu dan karakteristik pekerjaan terhadap kinerja karyawan pada Koperasi Simpan Pinjam "Abdi karya Sejahtera" Kendari dapat dinyatakan sebagai berikut :

$$
Y=0,264+0,456 X_{1}+0,355 X_{2}
$$

Dimana: $\mathrm{Y}=$ Kinerja Karyawan

$\mathrm{X}_{1}=$ Karakteristik Individu

$\mathrm{X}_{2}=$ Karakteristik Pekerjaan

$\mathrm{e}=$ standar eror

\section{Hasil Pengujian Model Regresi Secara Simultan}

Nilai $F_{\text {hitung }}=14,795$ dengan nilai signifikansi $F_{\text {sig }}=0,000$ yang berarti bahwa $F_{\text {sig }}<$ 0,05, maka secara statistika variabel karakteristik individu dan karakteristik pekerjaan secara simultan (bersama) berpengaruh signifikan terhadap kinerja karyawan pada Koperasi Simpan Pinjam "Abdi Karya Sejahtera" Kendari pada taraf kepercayaan $95 \%$.

\section{Hasil Pengujian Model Regresi Secara Parsial}

Hasil analisis regresi linear berganda pada lampiran yang diringkas seperti pada tabel 4.12, dapat diinterpretasikan sebagai berikut :

1. Signifikansi pengaruh variabel karakteristik individu $\left(\mathrm{X}_{1)}\right.$ terhadap kinerja karyawan $(\mathrm{Y})$, diperoleh nilai $\mathrm{t}_{\text {hitung }}\left(\mathrm{t}_{0,05}=2,968\right)$, dengan nilai signifikansi sebesar $t_{\text {sig }}=0,006$ yang berarti lebih kecil dari nilai $\alpha=0,05$. Hal ini menunjukan bahwa variabel karakteristik individu berpengaruh signifikan terhadap kinerja karyawan pada Koperasi Simpan Pinjam "Abdi Karya Sejahtera" Kendari, dengan demikian hipotesis diterima.

2. Signifikansi pengaruh variabel karakteristik pekerjaan $\left(\mathrm{X}_{1)}\right.$ terhadap kinerja karyawan $(\mathrm{Y})$, diperoleh $\mathrm{t}_{\text {hitung }}\left(\mathrm{t}_{0,05}=2,331\right)$ dengan nilai signifikan sebesar $t_{\text {sig }}=0,028$ yang berarti lebih kecil dari nilai $\alpha=0,05$. Hal ini menunjukan bahwa variabel karakteristik pekerjaan berpengaruh signifikan terhadap kinerja karyawan pada Koperasi Simpan Pinjam "Abdi Karya Sejahtera" Kendari, dengan demikian hipotesis diterima.

\section{Pembahasan}

\section{Pengaruh Karakteristik Individu Terhadap Kinerja Karyawan}

Hasil penelitian memperlihatkan bahwa secara parsial karakteristik individu mempunyai 
pengaruh yang signifikan terhadap kinerja karyawan pada Koperasi Simpan Pinjam "Abdi Karya Sejahtera" Kendari, karena didapat hasil uji parsial atau uji t sebesar 2,968 dengan signifikansi $0,006<$ tingkat signifikansi $\alpha=0,05$. Dengan demikian hipotesis pertama yang menyatakan bahwa karakteristik individu berpengaruh signifikan terhadap kinerja karyawan diterima. Penelitian ini secara deskriptif menunjukan bahwa total rata-rata skor kinerja dilihat dari faktor karakteristik individu rata-rata tinggi. Berarti, karakteristik individu memiliki pengaruh yang signifikan terhadap tinggi rendahnya kinerja karyawan pada Koperasi Simpan Pinjam "Abdi Karya Sejahtera" Kendari.

Temuan hasil penelitian ini sejalan dengan penelitian sebelumnya yang dilakukan oleh Hadrane di BPN Kabupaten Hulu Sungai Tengah (2017) bahwa secara parsial karakteristik individu berpengaruh positif dan signifikan terhadap kinerja pegawai. Dan temuan hasil penelitian pendukung, hasil penelitian Mutmainah (2012) dan Syah'bani (2012), yang menunjukan bahwa karakteristik inidividu berpengaruh terhadap kinerja pegawai. Semakin baik karakteristik individu terhadap organisasi maka akan semakin baik pula kinerjanya. Sebaliknya, semakin buruk karakteristik individu terhadap organisasi maka kinerja akan semakin menurun.

Hal ini disebabkan karena karakter setiap orang atau individu akan berbeda satu dengan lainnya. Karakter yang dimiliki seseorang tercermin melalui sikap dan tingkah lakunya. Pada instansi yang mempunyai banyak karyawan seperti Koperasi Simpan Pinjam "Abdi Karya Sejahtera" Kendari yang akan saling berinteraksi setiap harinya, maka akan banyak karakter individu yang akan saling berinteraksi setiap harinya. Para karyawan yang mempunyai karakter berbeda tersebut akan bersatu untuk bekerja demi kepentingan Koperasi Simpan Pinjam "Abdi Karya Sejahtera" Kendari. Karakter individu yang dimiliki setiap karyawan sulit akan diubah dan akan terbawa pada kehidupan sehariharinya termasuk dalam bekerja.

\section{Pengaruh Karakteristik Pekerjaan Terhadap Kinerja Karyawan}

Semakin baik karakteristik pekerjaan tercipta, maka semakin meningkat kinerja karyawan, begitu pula sebaliknya. Hal ini terbukti dari hasil analisis penelitian memperlihatkan bahwa secara parsial karakteristik pekerjaan mempunyai pengaruh yang signifikan terhadap kinerja karyawan pada Koperasi Simpan Pinjam "Abdi Karya Sejahtera" Kendari, karena didapat hasil uji parsial sebesar 2,311 dengan nilai signifikansi $0,028<$ tingkat signifikansi $\alpha=0,05$. Dengan demikian hipotesis kedua yang menyatakan bahwa karakteristik pekerjaan berpengaruh signifikan terhadap kinerja karyawan diterima.

Hal ini seseuai dengan teori yang disampaikan Robbins (2006) bahwa karakteristik pekerjaan merupakan salah satu faktor yang dapat mempengaruhi kinerja karyawan. Karakteristik pekerjaan menentukan kesesuaian orang dengan suatu bidang pekerjaan tertentu dan memungkinkan seseorang untuk lebih berhasil dalam bidang yang ditekuninya. Dengan pemahaman terhadap karakteristik pekerjaan diharapkan karyawan tersebut akan semakin berorientasi di bidang pekerjaannya. Karyawan akan menekuni pekerjaanya dengan kosentrasi dan tanggung jawab yang disertai dengan perasaan senang sampai diperoleh hasil yang memuaskan. Jika seseorang karyawan memiliki karakteristik yang sesuai dengan pekerjaannya maka kinerjanya akan meningkat.

Bentuk karakteristik pekerjaan yang ada di Koperasi Simpan Pinjam "Abdi Karya Sejahtera" Kendari yang mampu meningkatkan kinerja karyawan adalah keanekaragaman keterampilan, identitas tugas, signifikansi tugas, otonomi dan umpan balik. Karakteristik pekerjaan yang kuat dirasakan oleh karyawan akan dengan otomatis meningkatkan kinerjanya sesuai dengan standar kelengkapan dan ketelitian yang diberikan oleh Koperasi Simpan Pinjam "Abdi Karya Sejahtera" Kendari, selalu berusaha menyelesaikan semua tugas dengan baik sesuai dengan beban kerja yang diberikan, selalu berusaha menyelesaikan semua tugas sesuai dengan batas waktu yang telah ditentukan, selalu berusaha memiliki inisiatif dalam 
bekerja tanpa perlu diberitahu atau diinstruksikan dan selalu berusaha memiliki komitmen yang tinggi. Hal ini Seperti yang dikemukakan oleh Robbins (2001), Karakteristik pekerjaan merupakan upaya mengindentifikasi karakteristik tugas dari pekerjaanya, bagaimana karakteristik itu digabung untuk membentuk pekerjaan-pekerjaan yang berbeda, dan hubungannya dengan motivasi, kepuasaan dan kinerja karyawan. Penelitian ini sejalan dengan penelitian sebelumnya yang dilakukan oleh Andi Fadel Muhammad (2017) yang mengatakan bahwa karakteristik pekerjaan yang terdiri dari ragam keahlian, indentitas tugas, signifikansi tugas, otonomi berpengaruh positif dan signifikan terhadap kinerja pegawai pada Dinas Perizinan Kota Kendari.

\section{Pengaruh karakteristik individu dan karakteristik Pekerjaan secara simultan terhadap kinerja karyawan pada Koperasi Simpan Pinjam "Abdi Karya Sejahtera" Kendari.}

Hasil analisis data mengindikasikan bahwa variabel karakteristik individu dan karakteristik pekerjaan, secara simultan memberikan pengaruh yang signifikan terhadap kinerja karyawan Koperasi Simpan Pinjam "Abdi karya Sejahtera" Kendari. Hal ini berarti bahwa tinggi rendahnya kinerja karyawan Koperasi Simpan Pinjam "Abdi karya Sejahtera" Kendari selama ini dipengaruhi oleh karakteristik individu dan karakteristik pekerjaan.

Hasil Pengujian secara simultan dengan menggunakan nilai signifikansi $\mathrm{F}$ pada taraf $\alpha=$ 0,05 sebesar $0,000\left(F_{\text {sig }}=0,000\right)$ yang berarti nilai $\mathrm{F}_{\text {sig }}<\alpha=0,005$. Karena itu, secara keseluruhan atau secara bersama-sama karakteristik individu dan karakteristik pekerjaan berpengaruh terhadap kinerja karyawan.

Hal tersebut dipertegas pula dengan nilai koefisien determinasi yang diperoleh angka tersebut menunjukan bahwa terjadinya variasi variabel kinerja dapat dijelaskan oleh variabel karakteristik individu dan karakteristik pekerjaan. Dengan kata lain bahwa pengaruh langsung secara simultan dari kedua variabel tersebut adalah signifikan terhadap kinerja karyawan.
Selain itu, tingkat keeratan hubungan secara simultan dari kedua variabel karakteristik individu dan karakteristik pekerjaan terhadap kinerja menunjukan bahwa variabel karakteristik individu dan karakteristik pekerjaan memiliki keeratan hubungan dengan peningkatan atau penurunan kinerja.

Hasil penelitian secara deskriptif menunjukan bahwa total rata-tata skor kinerja adalah sangat tinggi. Artinya, tinggi rendahnya kinerja dipengaruhi oleh faktor karakteristik individu dan karakteristik pekerjaan. Temuan penelitian ini sesuai dengan penelitian Tisyantara Dwi Dityar Saputri (2016) yang mengatakan bahwa karakteristik individu dan karakteristik pekerjaan secara simultan (bersama-sama) mempunyai pengaruh signifikan terhadap kinerja karyawan. Artinya, semakin baik karakteristik individu dan karakteristik pekerjaan karyawan akan meningkatkan kinerjanya mereka dan begitupun sebaliknya.

Kinerja adalah hasil kerja secara kualitas dan kuantitas yang dicapai oleh seseorang pegawai dalam melaksanakan tugasnya sesuai dengan tanggung jawab yang diberikan kepadanya. Kinerja atau performance merupakan hasil perkalian antara kemampuan dengan karakteristik individu (Mangkunegara, 2010). Dengan hasil kinerja karyawan yang baik, maka akan berdampak pada kinerja organisasi. Organisasi berkewajiban untuk mempertahankan kinerja karyawan yang baik tersebut sehingga tujuan instansi / organisasi dapat dicapai dengan baik. Banyak faktor yang dapat mempengaruhi kinerja karyawan diantaranya adalah karakteristik individu dan karakteristik pekerjaan.

Menurut Luthans (2011:64), kinerja akan tercapai apabila pegawai merasa bahwa apa yang diperolehnya dari hasil kerja telah sesuai dengan apa yang diharapkan atau melebihi dari yang diharapkan. Karakteristik individu dan karakteristik pekerjaan adalah variabel yang berhubungan dan mempengaruhi kinerja (job performance). Karakteristik individu dan karakteristik pekerjaan memiliki implikasi, bukan saja pada pegawai dan organisasi, namun juga kepada masyarakat secara keseluruhan. 


\section{KESIMPULAN}

\section{Kesimpulan}

Berdasarkan hasil analisis dan pembahasan dalam penelitian ini, maka dapat disimpulkan bahwa :

1. Karakteristik individu berpengaruh secara signifikan terhadap kinerja karyawan pada Koperasi Simpan Pinjam "Abdi Karya Sejahtera" Kendari.

2. Karakteristik pekerjaan berpengaruh secara signifikan terhadap kinerja karyawan pada Koperasi Simpan Pinjam "Abdi Karya Sejahtera" Kendari.

3. Karakteristik individu dan karakteristik pekerjaan secara simultan berpengaruh secara signifikan terhadap kinerja karyawan pada Koperasi Simpan Pinjam "Abdi Karya Sejahtera" Kendari.

\section{Saran}

Berdasarkan kesimpulan hasil penelitian diatas, maka penulis mengajukan beberapa saran sebagai berikut :

1. Persepsi reponden atas variabel karakteristik pekerjaan memperoleh ratarata terendah dibandingkan dengan variabel karakteristik individu, walaupun persepsi responden sudah baik. Oleh karena itu, pihak instansi dalam meningkatkan kinerja harus memperhatikan karakteristik pekerjaan yang diberikan kepada karyawan, guna karyawan lebih termotivasi untuk bekerja.

2. Diharapkan peneliti berikutnya melakukan penelitian pada objek yang lain untuk memperluas pengetahuan mengenai karakteristik individu dan karakteristik pekerjaan, dan sampel yang digunakan dalam penelitian selanjutnya lebih banyak sehingga hasil lebih reprensetatif.

\section{DAFTAR PUSATAKA}

Hadrane, 2017. Pengaruh Karakteristik Inividu Dan Karakteristik Pekerjaan terhadap kinerja Pegawai di Kantor Badan Pertanahan Nasional Kabupaten Hulu Sungai Tengah. Jurnal Ilmiah Ekonomi Bisnis,Vol 3,No 1,Maret 2017, hal 124129.

Ghozali. 2001. "Aplikasi Analisis Multivariate dengan Program SPSS". Semarang: UNDIP.

Luthans Fred, 2011. Perilaku Organisasi. Edisi kesepuluh, Andi. Yogyakarta.

Mangkunegara. A. P. 2004, Manajemen Sumber Daya Manusia. PT Remaja Rosdakarya, Bandung.

.2009. Manajemen Sumber Daya Manusia. PT Remaja Rosdakarya, Bandung.

Mutmainah Hestin. 2012. "Pengaruh Karakteristik Individu dan Karakteristik Pekerjaan Terhadap Kinerja dengan Kepuasan Kerja sebagai Variabel Intervening di Lingkungan Kanwil Badan Pertanahan Nasional Provinsi Sumatera Barat”. E jurnal Bung Hatta.

Rendi Mahardika Moses, Endang Siti Astuti, dan Moh, Soe'oed Hakam, 2014. Pengaruh Karakteristik Individu dan Karakteristik Pekerjaan terhadap kinerja karyawan (Studi pada karyawan PT. Inti Bara Mandiri Tuban). Jurnal Administrasi Bisnis (JAB) Vol.12 No.1 juli 2014.

Robbins, Stephen P. 2007. Perilaku Organisasi ed. 10. Jakarta : PT Macanan Jaya Cemerlang.

2012. Perilaku Organisasi: Konsep, Kontroversi, dan Aplikasi. Prehallindo, Jakarta.

Sugiyono. 2014. Metode Penelitian Bisnis. Alfabeta. Bandung. 
2011. Metode Penelitian Bisnis. Alfabeta. Bandung.

Tika, P. (2006). Budaya Organisasi dan Peningkatan Kinerja Perusahaan. PT Bumi Aksara. Jakarta.

Tisyantari Dwi Dityar Saputri, 2016. Pengaruh Ka rakteristik Individu, Karakteristik Pekerjaan dan Lingkungan Kerja terhadap Kinerja Karyawan di PT BRI (Persero) Tbk Cabang Surabaya Kapas Krampung. Jurnal Ilmu dan Riset Manajemen : Volume 5, Nomor 8, agustus 2016.

Widiyanti, Ninik dan Y.W. Sunindhia. Koperasi dan Perekonomian Indonesia. Cetakan kelima. Jakarta: PT Rineka Cipta. 2008. 